\title{
ELABORACIÓN DE HARINA DE Smallanthus sonchifolius (POEPP.) H. ROB. "YACÓN" Y SU INFLUENCIA EN EL CRECIMIENTO DE DOS BACTERIAS PROBIÓTICAS
}

\author{
Elaboration of Smallanthus sonchifolius (Poepp.) H. Rob. "yacon" flour and its influence on \\ the growth of two probiotic bacteria \\ Daniel A. Coronado ${ }^{1}$, María E. Salazar² \\ ${ }^{1}$ Facultad de Farmacia y Bioquímica. ${ }^{2}$ Instituto de Investigación en Química Biológica, Microbiología y Biotecnología "Marco Antonio \\ Garrido Malo", Facultad de Farmacia y Bioquímica. Universidad Nacional Mayor de San Marcos
}

\section{RESUMEN}

Smallanthus sonchifolius Poepp \& Endl “yacón”, es una planta nativa de Sudamérica cuya raíz almacena carbohidratos en forma de inulina o fructooligosacáridos (FOS) (polímeros de fructosa), los cuales son reconocidos como fibra dietética y prebiótico. El presente trabajo tuvo como objetivo la elaboración de harina de yacón y estudiar su influencia en el crecimiento de dos bacterias probióticas. Mediante la evaluación y comparación de dos diseños: A con molienda de la raíz y B acondicionando el zumo, se pudo optimizar la obtención de harina para lograr mayor cantidad de azúcares totales y reductores, que fue 88,15 y 9,03\%, respectivamente. El diseño B se consideró como la mejor forma de producirla. En cuanto a la influencia sobre bacterias probióticas, se pudo apreciar que la harina de yacón mejora considerablemente el crecimiento de Lactobacillus acidophilus y Bifidobacterium breve.

Palabras clave: Harina de yacón, FOS, bacterias probióticas.

\section{SUMMARY}

Smallanthus sonchifolius Poepp \& Endl "yacon" is a native plant from South America, its root stores carbohydrates in the form of inulin or fructooligosaccharides (FOS) (polymers of fructose), which are recognized as dietary fiber and prebiotic. This study aimed to elaborate yacon flour and investigate its influence in growth of two probiotic bacteria. By the evaluation and comparing two designs: A with grinding of the root and $\mathrm{B}$ conditioning the juice, it was able to optimize the production of flour, obtaining an improvement in the amount of total and reducing sugars, which were 88,15 and 9,03\%, respectively. The B design was the best way to get yacon flour. About the influence on probiotic bacteria, was observed that yacon flour improve considerably the growth of Lactobacillus acidophilus and Bifidobacterium breve.

Keywors: Yacon flour, FOS, probiotic bacteria.

\section{INTRODUCCIÓN}

E 1 enfoque que existe sobre alimentación y salud en los países occidentales han provocado intenso interés en la identificación de nuevos alimentos e ingredientes funcionales para prevenir enfermedades específicas (diabetes, obesidad, etc.). América del Sur posee amplia variedad de plantas con potencial olvidado, por lo que son poco utilizadas. Uno de estos activos redescubierto, es el Smallanthus sonchifolius Poepp \& Endl “yacón”, que es una fuente muy abundante de fructooligosacáridos (FOS) ${ }^{1,2}$, carbohidratos compuestos principalmente por fructosa y escasos residuos de glucosa, considerados como prebióticos que cumplen con todos los criterios de clasificación y seguridad alimentaria ${ }^{3}$.

Los prebióticos son ingredientes no digeribles de la dieta_que producen efectos beneficiosos estimulando selectivamente el crecimiento o actividad de uno o más tipos de bacterias en el colon, que a su vez tienen la propiedad de elevar el potencial de salud del consumidor. Los probióticos son microorganismos vivos, que al ser agregados como suplemento en la dieta, afectan en forma beneficiosa el desarrollo de la flora microbiana en el intestino ${ }^{4}$.

El colon humano constituye un complejoecosistema de diferentes especies de bacterias cuya actividad y cantidad se ve afectada por la fisiología gastrointestinal y por los sustratos de fermentación con que dispongan ${ }^{5}$. En este órgano son fermentados los FOS deforma selectiva por muchas bacterias probióticas como bifidobacterias, lactobacilos, entre otros.) Las bifidobacterias, que constituyen hasta un $25 \%$ de la flora del colon, al fermentar los fructanos, contribuyen a la disminución y hasta eliminación de cepas patogénicas sensibles al medio ácido, por liberación de bacteriocinas y competencia por los sitios de adhesión, entre otros ${ }^{6}$.

El yacón es una raíz tuberosa oriunda de la región andina, domesticada desde épocas preincaicas. Contiene grandes cantidades de FOS de tipo inulina (50 a 60\% de masa seca), que son azúcares con propiedades benéficas para la salud, como la capacidad para estimular el desarrollo de bifidobacterias en el intestino humano y presentar bajo valor calórico ( 1 a $3 \mathrm{Kcal} / \mathrm{g}$ ) ${ }^{9}$. Son de interés para la industria alimentaria, como edulcorante alternativo a la sacarosa o como alimento funcional ${ }^{7,8}$. A diferencia de otras fuentes de este tipo de carbohidratos, el yacón es tan rico en ellos, que una dosis efectiva está garantizada por el consumo de una cantidad moderada de la raíz, la cual se describe como agradable al paladar, y de la que pueden extraerse directamente los FOS sin necesidad de proceso de transformación alguno.

Los FOS se emplean en la elaboración de alimentos nutracéuticos o funcionales, es decir aquellos alimentos 
que independientemente de su valor nutritivo ejercen un efecto favorable sobre la salud del consumidor ${ }^{9}$. Como el mercado para este tipo de productos está en expansión, el yacón podría posicionarse en él, sin embargo, su potencial no se limita a ello, pues también se puede obtener una gama de productos procesados que permitirían generar valor agregado, con los que desarrollaría y afianzaría aceptación; uno de estos derivados es la harina de yacón. Por ello el presente trabajo tuvo como objetivos la elaboración de harina de Smallanthus sonchifolius "yacón", estudiar su contenido de azúcares y evaluar la influencia de éstas en el crecimiento de dos bacterias probióticas.

\section{MATERIAL Y MÉTODOS}

El presente trabajo es experimental y prospectivo. Se desarrolló en el laboratorio de Farmacognosia y en el Instituto de Química Biológica, Microbiología y Biotecnología "Marco Antonio Garrido Malo" de la Facultad de Farmacia y Bioquímica.

La recolección de las muestras de yacón se realizó a 2100 m dealtitud, en la localidad de Jaipe, distrito de Lonya Grande, provincia de Utcubamba en el departamento de Amazonas. La muestra fue estudiada y clasificada científicamente como Smallanthus sonchifolius (Poepp.) H. Rob., ocupando las siguientes categorías taxonómicas:

División : Magnoliophyta
Clase : Magnoliopsida
Sub Clase: Asteridae
Orden : Asterales
Familia : Asteraceae
Género : Smallanthus
Especie : Smallanthus sonchifolius (Poepp.) H. Rob.

El resto de la planta fue almacenada a $5^{\circ} \mathrm{C}$ para su respectivo análisis y elaboración de harina.

Para mejor uniformidad dela muestra, se hizola selección de raíces en base a diámetro promedio, longitud y peso.

\section{Obtención de la harina}

La elaboración de la harina se realizó de dos formas: A: molienda de la raíz; y B: acondicionando la muestra (zumo de yacón) ${ }^{8}$.

Selección: se seleccionó la materia prima separando las muestras que estaban maltratadas, resecas u oscuras. Lavado y desinfectado: las raíces se lavaron para eliminar residuos indeseables presentes. La desinfección se realizó con una solución de hipoclorito de sodio $2 \%$ para eliminar posibles microorganismos adheridos a la muestra. Pelado: fue de forma manual con la ayuda de peladores de acero inoxidable, se utilizó ácido ascórbico o,o $7 \%$ como antioxidante para prevenir el pardeamiento enzimático y preservar el color. Troceado: las raíces se redujeron de tamaño hasta un espesor aproximado de $15 \mathrm{~mm}$, de esta manera se optimizó el proceso de blanqueado. Escaldado o blanqueado: se sometió la materia prima a un baño de agua hirviendo $\left(92^{\circ} \mathrm{C}\right)$ con la finalidad de: a) terminar la limpieza del producto, b) provocar la destrucción de oxidasas que pardean el producto, c) fijar y conservar el color y, d) mejorar las condiciones del material para la desecación. El proceso de escaldado contribuye a una esterilización parcial, puesto que la elevada temperatura que alcanza destruye los microorganismos.

\section{Obtención de harina según el diseño A:}

Molienda: luego del paso anterior, parte de las muestras se trituraron en un molino de martillos para obtener la harina según el diseño A.

\section{Obtención de harina según el diseño $B$ :}

Obtención del zumo: las muestras restantes fueron licuadas y filtradas en telas de tocuyo para eliminar sólidos insolubles y restos groseros, facilitando la evaporación y la concentración de azúcar (grados Brix). Concentración: el zumo fue colocado en baño maría a $60^{\circ} \mathrm{C}$ hasta $20^{\circ} \mathrm{Bx}$ en promedio, con la finalidad de reducir el peso y el volumen y así facilitar el proceso de secado ${ }^{4}$. Secado: la muestra obtenida se trasvasó a bandejas de acero inoxidable para eliminar el resto de agua contenida en la raíz en una estufa a 60 y $40^{\circ} \mathrm{C}$ por al menos 48 horas. El secado concluyó cuando el producto se tornó duro y quebradizo. Molienda: se molió el producto deshidratado en molino de cuchillas obteniéndose harina según el diseño $B$.

Las muestras fueron envasadas en bolsas de polietileno de alta densidad y selladas con el fin deasegurar el aislamiento completo del medio ambiente (oxígeno, humedad) y contribuir a su conservación. Ambos productos obtenidos fueron sometidos a análisis químicos y a la evaluación de la actividad prebiótica.

\section{Análisis químicos}

Se realizó el análisis proximal, determinación de sólidos solubles y $\mathrm{pH}$, según AOAC ${ }^{\mathbf{1 0}}$.

Se determinó la concentración de azúcares reductores, mediante el ensayo del ácido dinitrosalicílico (DNS) que en medio alcalino reacciona con el grupo reductor de la glucosa formando un compuesto de color rojo cuya intensidad es proporcional a la cantidad de azúcares reductores presentes, expresados como glucosa equivalente. Para esta prueba se añadieron DNS (1 mL) y agua (1 mL) a cada muestra y a una solución de glucosa estándar (1 mL), llevándose a ebullición por 15 minutos, para luego enfriarlas en baño de hielo por 2 minutos. Luego se fue añadiendo agua $(9 \mathrm{~mL})$ y se midió la absorbancia a una longitud de onda de $540 \mathrm{jm}$. El contenido de azúcares reductores de la muestra se comparó con la curva estándar de glucosa ${ }^{2,6,9}$.

Se determinó la concentración de azúcares totales 2, 6, 9, con el método del ácido sulfúrico-fenol que fue calibrado con D-glucosa estándar de o a $100 \mu \mathrm{g} / \mathrm{mL}$ y los resultados expresados en equivalentes de glucosa. A las muestras y a una solución estándar de glucosa $(1 \mathrm{~mL})$ se les añadió solución de fenol 5\% (1 mL) y ácido sulfúrico concentrado $(5 \mathrm{~mL})$ agitándose 10 minutos. Luego se dejaron en reposo por 20 minutos a temperatura ambiente y después se midió la absorbancia a $490 \mathrm{\eta m}$.

\section{Análisis microbiológicos}

Se prepararon inóculos por triplicado, para los oligosacáridos provenientes de las harinas A y B y un control.

El inóculo de Lactobacillus acidophilus se cultivó en caldo MRS a $37^{\circ} \mathrm{C}$ por 48 horas hasta obtener una concentración de $5 \times 10^{7} \mathrm{ufc} / \mathrm{mL}$ y luego se diluyó con 250 
Tabla 1. Características físicas de la raíz de yacón.

\begin{tabular}{lccc} 
& Promedio & Mínimo & Máximo \\
\hline Peso (g) & 401,64 & 260,95 & 715,95 \\
Diámetro central (cm) & 4,25 & 2,30 & 5,45 \\
Longitud (cm) & 21,71 & 15 & 25 \\
Color (pulpa) & & Amarillo & \\
Color (cáscara) & Marrón \\
\hline
\end{tabular}

Tabla 2. Análisis proximal de las muestras de harina de yacón obtenidas según dos diseños.

\begin{tabular}{lcc}
\hline \multicolumn{1}{c}{ Componentes } & Diseño A (\%) & Diseño B (\%) \\
\hline Humedad & 2,58 & 2,30 \\
Cenizas & 3,09 & 2,98 \\
Proteína total & 5,52 & 5,50 \\
Fibra & 0,85 & 0 \\
Grasa & 0,93 & 1,07 \\
Carbohidratos & 87,03 & 88,15 \\
\hline
\end{tabular}

Tabla 3. Recuento de L. acidophilus.

\begin{tabular}{lcccc}
\hline \multirow{2}{*}{ Muestra } & \multicolumn{4}{c}{ Recuento microbiano (UFC/ $\mathbf{m L}$ ) } \\
\cline { 2 - 5 } & $\mathbf{0 ~ h}$ & $\mathbf{2 4 ~ h}$ & $\mathbf{4 8 ~ h}$ & $\mathbf{7 2 ~ h}$ \\
\hline $\begin{array}{l}\text { Inóculo (control) } \\
\text { Inóculo + harina obtenida }\end{array}$ & $3 \times 10^{4}$ & $1,0 \times 10^{6}$ & $2 \times 10^{7}$ & $5 \times 10^{8}$ \\
$\begin{array}{l}\text { según el diseño A } \\
\text { Inóculo + harina obtenida } \\
\text { según el diseño B }\end{array}$ & $6 \times 10^{4}$ & $1,08 \times 10^{6}$ & $4 \times 10^{7}$ & $7 \times 10^{8}$ \\
\hline
\end{tabular}

Tabla 4. Absorbancias de L. acidophilus.

\begin{tabular}{lcccc}
\hline \multirow{2}{*}{ Muestra } & \multicolumn{4}{c}{ Absorbancia (A) } \\
\cline { 2 - 5 } & $\mathbf{0 ~ h}$ & $\mathbf{2 4} \mathbf{~ h}$ & $\mathbf{4 8 ~ h}$ & $\mathbf{7 2 ~ h}$ \\
\hline $\begin{array}{l}\text { Inóculo (control) } \\
\text { Inóculo + harina obtenida }\end{array}$ & 0,016 & 0,243 & 0,464 & 0,908 \\
$\begin{array}{l}\text { por según el diseño A } \\
\text { Inóculo + harina obtenida } \\
\text { por según el diseño B }\end{array}$ & 0,072 & 0,105 & 0,433 & 0,939 \\
\hline
\end{tabular}

Tabla 5. Recuento de B. breve.

\begin{tabular}{lcccc}
\multirow{2}{*}{\multicolumn{1}{c}{ Muestra }} & \multicolumn{4}{c}{ Recuento microbiano (UFC/ mL) } \\
\cline { 2 - 5 } & $\mathbf{0 ~ h}$ & $\mathbf{2 4 ~ h}$ & $\mathbf{4 8 ~ h}$ & $\mathbf{7 2 ~ h}$ \\
\hline $\begin{array}{l}\text { Inóculo (control) } \\
\text { Inóculo + harina obtenida }\end{array}$ & $3 \times 10^{4}$ & $1,0 \times 10^{6}$ & $2 \times 10^{7}$ & $1,10 \times 10^{8}$ \\
$\begin{array}{l}\text { según el diseño A } \\
\text { Inóculo + harina obtenida } \\
\text { según el diseño B }\end{array}$ & $6 \times 10^{4}$ & $1,28 \times 10^{6}$ & $4 \times 10^{7}$ & $2,3 \times 10^{8}$ \\
\hline
\end{tabular}

Tabla 6. Absorbancias de B. breve.

\begin{tabular}{|c|c|c|c|c|}
\hline \multirow{2}{*}{ Muestra } & \multicolumn{4}{|c|}{ Absorbancia (A) } \\
\hline & $\mathbf{O h}$ & $24 \mathrm{~h}$ & $48 \mathrm{~h}$ & $72 \mathrm{~h}$ \\
\hline Inóculo (control) & 0,019 & 0,243 & 0,433 & 0,581 \\
\hline $\begin{array}{l}\text { Inóculo + harina obtenida } \\
\text { por según el diseño A }\end{array}$ & 0,029 & 0,274 & 0,453 & 0,608 \\
\hline $\begin{array}{l}\text { Inóculo + harina obtenida } \\
\text { por según el diseño B }\end{array}$ & 0,038 & 0,296 & 0,464 & 0,624 \\
\hline
\end{tabular}

$\mathrm{mL}$ de caldo MRS hasta una concentración de $5 \times 10^{4} \mathrm{ufc} /$ $\mathrm{mL}$. Se prepararon soluciones al $1 \% \mathrm{p} / \mathrm{v}$ de las muestras y se añadieron a los caldos con inóculo. Se incubaron a $37^{\circ} \mathrm{C}$ por 72 horas en condiciones anaeróbicas.

La otra cepa probiótica, Bifidobacterium breve, fue cultivada en caldo MRS reforzado con clorhidrato de cisteína $(0,5 \mathrm{~g} / \mathrm{L})$, dicloxacilina $(0,05 \mathrm{~g} / \mathrm{L})$ y cloruro de litio ( $2 \mathrm{~g} / \mathrm{L})$. El inóculo se incubó a $37^{\circ} \mathrm{C}$ por 48 horas para obtener una concentración de $5 \times 10^{7}$ ufc/mL que se diluyó con $250 \mathrm{~mL}$ de caldo MRS reforzado para obtener una concentración de $5 \times 10^{4} \mathrm{ufc} / \mathrm{mL}$, luego se añadieron las soluciones de las muestras al $1 \% \mathrm{p} / \mathrm{v}$ y se incubaron a $37^{\circ} \mathrm{C}$ por 72 horas en condiciones anaeróbicas.

\section{Evaluación del crecimiento por espectrofotometría y recuento por dilución}

Se tomaron muestras al inicio y a las 24,48 y 72 horas, midiéndoseen cadauna laabsorbanciaa 500 ymy realizando diluciones seriadas de $1 / 10^{5}$ a $1 / 10^{9}$ que se sembraron por incorporación en agar MRS para L. acidophilus y agar MRS reforzado para B. breve, por duplicado. Luego se incubaron en condiciones apropiadas por 72 horas a $37^{\circ} \mathrm{C}$ y se realizó el recuento expresado en ufc/mL.

\section{RESULTADOS}

Los datos correspondientes a las medidas de diámetro, longitud y peso se aprecian en la tabla 1.

La cuantificación de los componentes de las muestras de harina obtenidas por los dos diseños, se realizó mediante el análisis proximal, los resultados se exhiben en la tabla 2.

El porcentaje de azúcares reductores y $\mathrm{pH}$ para la harina obtenida por el diseño A fueron $7,65 \%$ y 4,40, respectivamente, mientras que para la obtenida según $B$ fueron $9,03 \%$ y 4,49 , respectivamente.

Los promedios de los resultados de la evaluación de la actividad prebiótica de ambas harinas con cada microorganismo, se expresaron como recuentos (ufc/mL) a las o, 24, 48 y 72 horas (tablas 3y 5), y como absorbancias (tablas 4 y 6).

\section{DISCUSIÓN}

Los carbohidratos representan alrededor del 90\% del peso seco de las raíces del yacón ${ }^{11}$. Los resultados obtenidos, se aproximan mucho a los de Seminario ${ }^{1}$, que reportó una concentración de carbohidratos y valores de azúcares reductores para la segunda cosecha muy cercanos a los del presente estudio, aunque en cuanto al $\mathrm{pH}$ aquí se evidenció ligera acidez. Dicha similitud podría deberse a que Cajamarca y Amazonas presentan condiciones climáticas relativamente parecidas.

Es importante mencionar que en el proceso de obtención de la harina de yacón, el secado fue artificial y esto evita significativamente que disminuya la cantidad de fructanos en comparación con el tratamiento solar, donde parte de ellos se convierten en fructosa ${ }^{12}$.

Al yacón se le han atribuido efectos benéficos a nivel gastrointestinal, pues mejora la flora microbiana y la respuesta del sistema inmunológico, lo que previene infecciones intestinales ${ }^{13}$. El presente estudio podría reforzar la afirmación referente a la flora, puesto que el resultado de los recuentos indica que la harina obtenida, incrementó la cantidad de Lactobacillus acidophilus a lo largo del tiempo.

Entre las dos formas de harina obtenidas, el mejor resultado -en lo referente a L. acidophilus - se logró con el diseño B, sobre todo al tercer día de incubación, posiblemente porque contiene mayor cantidad de 
azúcares, lo que concuerda con lo reportado por Kaplan et al. quienes trabajaron con con L. paracasei ${ }^{14}$.

El crecimiento de Bifidobacterium breve no mostró diferencia considerable entre ambas harinas, posiblemente porque esta bacteria es más exigente nutricionalmente y la mejora en su multiplicación requeriría la presencia de otros factores de crecimiento. La modulación de la comunidad bacteriana intestinal hacia una dirección benéfica, ya sea alimentando con bacterias vivas (probióticos) o con carbohidratos especializados (prebióticos) para estas bacterias favorecedoras, puede ser lograda cambiando la dinámica intestinal a través de las modulaciones dietéticas ${ }^{15}$.

Los resultados indican que se podría utilizar la harina de yacón como alimento prebiótico para favorecer el crecimiento de microorganismos que forman parte de la flora microbiana no sólo humana sino también animal ${ }^{16}$. Además, por ser perecibles, requieren de procesamiento, lo que ofrecería diversas alternativas a la comercialización tradicional de las raíces frescas ${ }^{17,18}$, una de las cuales sería la elaboración de harina bajo condiciones óptimas que mantengan los valores de sus principales componentes.

\section{CONCLUSIONES}

La mayor cantidad de carbohidratos (azúcares totales y reductores) se encuentran en la harina obtenida por el diseño B.

Los azúcares presentes en la harina de yacón obtenida por los diseños A y B estimulan el crecimiento de Lactobacillus acidophilus incrementando su número de $5 \mathrm{x}$ $10^{4}$ a $7 \times 10^{8}$ y de $6 \times 10^{4}$ a $1,3 \times 10^{9} \mathrm{ufc} / \mathrm{mL}$, respectivamente, así como también actúan estimulando el crecimiento de Bifidobacterium breve incrementando su número de $5{\mathrm{X} 10^{4}}^{4}$ a $2,3 \times 10^{8}$ y $6 \times 10^{4}$ a $2,78 \times 10^{8} \mathrm{ufc} / \mathrm{mL}$, respectivamente.

\section{Agradecimiento}

Al VRI de la UNMSM por el financiamiento Proyecto $\mathrm{N}^{\circ}$ 110400097.

\section{REFERENCIAS BIBLIOGRÁFICAS}

1. Seminario J, Valderrama M, Manrique I. Yacón: Fundamentos para el aprovechamiento de un recurso promisorio. Centro Internacional de la Papa, Universidad Nacional de Cajamarca, Agencia Suiza para el Desarrollo y la Cooperación. Lima; 2003.

2. Chávarry R. Influencia en las condiciones de almacenaje del yacón fresco (Smallanthus sonchifolius Poepp. \& Endl.) en sus compuestos bioactivos. [Tesis]. Universidad Nacional Agraria. Lima, 2007.

3. Chacón A. Perspectivas agroindustriales actuales de los oligofructosacáridos (FOS). Agron Mesoam. 2006; 17(2): 265-86.

4. Ávila J, Ávila M, Tovar B, Brizuela M, Perazzo Y, Hernández H. Capacidad probiótica de cepas del género Lactobacillus extraídas del tracto intestinal de animales de granja. Rev Cient Maracaibo. 2010; 20(2): 161-70.

5. Mabel MJ, Sangeetha PT, Platel K, Srinivasan K, Prapulla SG. Physicochemical characterization of fructooligosaccharides and evaluation of their suitability as a potential sweetener for diabetics. Carbohydr Res. 2008; 343(1): 56-66.

6. López-Molina D, Navarro-Martínez MD, Rojas F, Hiner AN, Chazarra S, Rodríguez-López JN. Molecular properties and prebiotic effect of inulin obtained from artichoke (Cynara scolymus L.). Phytochemistry. 2005; 66(12): 1476-84.

7. Faustino A. Extrato aquoso de Yacon (Smallanthus sonchifolius) desidratado por atomizacao. [Tesis de Maestría]. Universidade Federal de Goias. Goiania, 2012.

8. Ojansivu I, Ferreira CL, Salminen S. Yacon, a new source of prebiotic oligosaccharides with a history of safe use. Trends Food Sci Tech. 2011; 22(1): 40-6.

9. Wichienchot S, Jatupornpipat $M$, Rastall RA. Oligosaccharides of pitaya (Dragon fruit) flesh and their prebiotic properties. Food Chem. 2010; 120(3): 850-7.

10. AOAC. Oficial methods of analysis of AOAC International. $16^{\text {th }}$ ed. Arlington: AOAC Inc, 1995.

11. Lachman J, Fernández EC, Orsák M. Yacón (Smallanthus sonchifolius Poepp. Et Endl. H. Robinson) chemical composition and use - a review. Plant Soil Environ. 2003; 49(6): 283-90.

12. Carvalho S, Toledo I, Araujo F, Pereira G. Fructanos en raíces tuberosas de yacón (Smallanthus sonchifolius Poepp. and Endl.) expuestas al sol y almacenadas bajo condiciones ambientales. Agro-Ciencia. 2004; 20(1): 17-23.

13. Roberfroid M. Concept in functional foods: the case of inulin and oligofructose. J Nutr. 1999; 129 Suppl 7: S1398401.

14. Kaplan H, Hutckins R. Metabolism of fructooligosaccharides by Lactobacillus paracasei 1195. Appl Environ Microbiol. 2003; 69(4): 2217-22.

15. Apajalahti J. Comparative gut microflora, metabolic challenges, and potential opportunities. J Appl Poult Res. 2005; 14(2): 444-53.

16. Fuentes N, Figueroa E, Carcelén F, Arbaiza T. Harina de Yacón (Smallanthus sonchifolius) como prebiótico en dietas de patos Muscovy (Cairina moschata) en etapa de engorde. Rev Inv Vet Perú. 2012; 23(1): 105-11.

17. Gonzáles H. Evaluación de la harina de yacón (Smallanthus sonchifolius) como prebiótico en dietas de pavos de engorde. [Tesis]. Universidad Nacional Mayor de San Marcos, 2009.

18. Indecopi. Boletín BioPat Perú. Tema: Yacón. [Internet]. Abril 2015 [Citado 22 julio 2016]; 1(4): 1-20. Disponible en https://www.indecopi.gob.pe/ documents/20791/202940/o4.-Boletin4_YACON.pdf

Manuscrito recibido el: 16/03/2016

Aceptado para su publicación el: 19/09/2016

\section{Correspondencia}

Nombre: María Elena Salazar Salvatierra

Dirección: Jr. Puno 1002 - Lima

e-mail: msalazars@unmsm.edu.pe 